\title{
Turismo religioso como fonte de
} desenvolvimento local: um estudo acerca da produção do espaço urbano a partir da prática turística religiosa

Religious tourism as source of local development: a study on the production of urban space from religious tourism practice

Lorrana Laila Silva de Almeida - Iorranalaila.adm@bol.com.br

Alessandro Gomes Enoque - alessandroenoque@ufu.br

Antonio de Oliveira Júnior antonio.oliveira@ufu.br

\section{RESUMO}

O Turismo compreende um setor de atividade que movimenta, de forma significativa, a cultura e a economia de determinado país, emergindo em transformações que colaboram para o desenvolvimento local. Nessa conjuntura, surge 0 turismo religioso como fonte geradora de empregabilidade, movimentando vários setores da economia, como o hoteleiro e o alimentício, além de estimular o consumo de artigos religiosos e artesanais. Assim posto, este ensaio teórico tem como foco incitar uma reflexão acerca da relação existente entre o turismo religioso e suas implicações no espaço urbano, demonstrando a importância desse setor de atividade para a cultura e a economia do país, além de evidenciar as transformações produzidas na dinâmica local das cidades em que ele é praticado, contribuindo na exploração da temática para o campo do turismo e áreas afins. Como resultado fica evidente a influência do turismo religioso no desenvolvimento das cidades, impactando na conjuntura local, ao passo que amplia as possibilidades de novos mercados e criação de novos empregos movimentando, de forma significativa, a economia e contribuindo na produção do espaço urbano.

Palavras-chave: Turismo religioso, turismo urbano, desenvolvimento local, cultura. 


\section{ABSTRACT}

Tourism comprises a sector of activity that significantly changes the culture and economy of a given country, emerging in transformations that contribute for local development. In this scenario, religious tourism emerges as a source of employability, moving various sectors of economy, such as hotel and food sectors, as well as stimulating the consumption of religious and craft articles. In this context, this theoretical essay aims to stimulate a reflection on the relationship between religious tourism and its implications in urban space. It demonstrates the importance of this sector for the country's culture and economy, as well as it highlights the implications of the local dynamics of the cities in which it is practiced, which contributes for the expansion of this theme in the field of tourism and related areas. As a result, the influence of religious tourism on the development of cities is evident, causing impacts on the local context, while expanding the possibilities of new markets and the creation of new jobs, significantly moving the economy and contributing to the production of urban space.

Keywords: Religious tourism, urban tourism, local development, culture.

\section{INTRODUÇÃO}

Estudos cujo enfoque é a discussão sobre religiosidade têm assumido uma representatividade no campo de pesquisas acadêmicas científicas, sendo a temática amplamente explorada e difundida na área de estudos organizacionais (Silva, Pontes, Batalha \& Bentes, 2014; Enoque, Borges \& Borges, 2016; Borges, Enoque, Katrib \& Gonçalves, 2016; Borchardt \& Bianco, 2016; Quezado, Frota, Costa, Arruda \& Mota, 2016; Bazanini \& Giglio, 2017; Bazanini \& Machado Junior, 2018; Flausino, Medeiros \& Valadão Júnior, 2018). Essa abordagem enriquece o campo do conhecimento, ao passo que possibilita uma dinamicidade de novas descobertas, principalmente pela discussão do escopo religioso atrelado a diversos campos de investigação, dentre estes, o campo do turismo (Bastos, Salles \& Bueno, 2014; Aragão, 2015; Schneider \& Santos, 2015; Boulhosa, 2017; César, Belusso \& Silva, 2017).

Entendido como um fenômeno social de dinâmica própria, o 
turismo compreende um setor de atividade que movimenta, de forma significativa, a cultura e a economia de determinado país, emergindo em transformações que colaboram para o desenvolvimento das cidades, impactando diretamente na vida da população e na conjuntura do espaço urbano. Assim, é possível inferir que a atividade turística assume forte influência na dinamicidade dos lugares de visitação, resultando em transformações sociais, políticas, econômicas e culturais, as quais são refletidas no contexto onde o turismo é praticado (Barbosa, 2005; Xavier, 2006; Cordeiro, 2008; Dall'Agnol, 2012; Becker, 2014; Carvalho, \& Viana, 2014; Barcellos, 2016).

Desse conjunto de transformações das cidades, emerge o turismo religioso, o qual pode ser entendido como uma atividade de forte representatividade econômica, que tem como princípio fundamental a fé, envolvendo a participação de pessoas que se deslocam por motivos religiosos ou que objetivam participar de algum evento de cunho religioso, como a prática das peregrinações (Maio, 2004; Pereira, 2017; Silva \& Silva, 2017; Curado \& D'abadia, 2018; Erig, Santana \& Ferreira, 2018; Morajácome, Ludeña-reyes, Ochoa-ochoa \& Sánchez-cevallos, 2018; Soares \& Ramos, 2018; Frías, 2019; Kunt \& Meydan-uygur, 2019; Sanchez \& Fernandezhernandez, 2019).

Para compreender a amplitude desse setor de atividade, objeto de investigação desse ensaio teórico, vale ressaltar que de acordo com estimativas apresentadas pelo Ministério do Turismo ([Mtur], 2015), só no ano de 2014 as viagens relacionadas ao turismo religioso envolveram cerca de 17,7 milhões de peregrinos que percorreram o Brasil movidos por suas crenças religiosas. Em consonância ao exposto, é notório o crescimento do turismo religioso no país, movimentando diretamente a economia de diversas regiões brasileiras, como é o caso da cidade de Aparecida, localizada no interior do estado de São Paulo, que recebe por ano cerca 
de 12 milhões de turistas (Jornal de Turismo, 2015).

Todavia, cabe salientar que, apesar da forte representatividade católica, a abordagem do turismo religioso brasileiro compreende diversas atrações de outras religiões como evangélicas, budistas e também espíritas (Feira Internacional de Turismo [FESTURIS Gramado], 2018).

Com isso, percebe-se que o turismo religioso se caracteriza por seu considerável impacto no país e essa realidade, por sua vez, origina transformações na dinâmica local, gerando empregabilidade e movimentando vários setores da economia, como o hoteleiro e o alimentício, além de estimular o consumo de artigos religiosos e artesanais, tendo em vista que cada localidade possui produtos característicos comercializados no contexto dessa atividade (MTUr, 2015; FESTURIS Gramado, 2018).

A partir do exposto, este estudo objetiva incitar uma reflexão acerca da relação existente entre o turismo religioso e suas implicações no espaço urbano, evidenciando as transformações produzidas na dinâmica local das cidades em que o turismo religioso é praticado, além de demonstrar a importância desse setor de atividade para a cultura e a economia do país, contribuindo, assim, na exploração da temática e ampliando conhecimentos para o campo do turismo e áreas afins.

Em adição, este ensaio teórico propõe ao leitor alguns questionamentos acerca do papel e da prática turística, versando sobre os impactos positivos, mas também instigando reflexões sobre os possíveis impactos negativos decorrentes dessa atividade. Assim posto, é possível que o turismo seja trabalhado na conjuntura das cidades, de forma a contribuir para o desenvolvimento, sem impactar de forma negativa, priorizando determinadas esferas políticas, econômicas e, principalmente, sociais? O turismo pode proporcionar desenvolvimento, disseminar uma boa imagem das cidades na mídia e, ainda assim, ocultar uma 
realidade urbana que desagrega e exclui, privilegiando aqueles que estão em lugar de dominância? Para aqueles que residem nas cidades, o turismo é percebido apenas do ponto de vista positivo, ou as populações possuem um outro olhar acerca da prática turística que não é exposta, mas sim, negligenciada? E, por fim, como é possível manter a tradição de algumas atividades passadas de geração para geração, uma vez que a inserção do turismo pode acarretar a substituição destas atividades tradicionais praticadas pelas populações das cidades, estimulando as pessoas a buscarem novas formas de trabalho, abolindo a própria cultura de atividade tradicional local?

\section{TURISMO E ESPAÇO URBANO: ALGUMAS CONSIDERAÇÕES}

O turismo pode ser entendido como a movimentação de indivíduos os turistas -, que se deslocam do próprio contexto de vida em busca de uma particularidade em comum: conhecer e vivenciar experiências em lugares que promovam lazer, distração, entretenimento e novas descobertas. Por sua vez, o turismo compreende certa complexidade em sua concepção, englobando as atividades de oferta, as tendências, gestão e planejamento, corroborando, assim, na criação de valor que os visitantes atribuem às experiências e às sensações adquiridas a partir da prática turística (Banducci \& Barreto, 2001; Souza, 2010; Barbosa, 2012; Ramos \& Costa, 2017; Camargo, 2019; Trindade, César \& Vianna, 2019).

Nesse sentido, o turismo pode ser apontado como um fenômeno social, considerando que, ao reunir um número significativo de pessoas em uma mesma localidade, estas passam a ser vistas como habitantes temporários, refletindo em grandes impactos na sociedade, com destaque para a conjuntura econômico-financeira.

Os resultados que a atividade turística é capaz de obter decorrem da movimentação econômico-financeira pelo deslocamento de pessoas de seu local habitual de residência para outros, desde que 
esse deslocamento seja espontâneo e de permanência temporária. Ao analisar o fenômeno turismo deve levar em conta dois aspectos importantes: o interesse dos turistas e o interesse do local que recebe os turistas. O primeiro deles procura regiões que oferecem atividades que ocupem seu tempo livre e que atendam a seus interesses. 0 segundo visa atrair os turistas para ocupar seu tempo livre por meio das atrações que já possui ou que pode criar. O relacionamento entre essas duas partes produz resultados que levam o local visitado ao desenvolvimento econômico, à medida que a localidade se organiza e dinamiza o setor turístico (Barbosa, 2005, p. 108).

Importante destacar nessa conjuntura que um dos aspectos mais peculiares que envolvem a prática do turismo estaria relacionado ao fato de que tal atividade proporciona uma junção de diferentes culturas, emergindo para turistas e residentes das cidades visitadas a experiência da alteridade, ou seja, a troca de conhecimentos e diversidades por meio da interação que se estabelece entre as pessoas que habitam aquele espaço e os indivíduos vindos de outras localidades (Banducci \& Barreto, 2001; Souza, 2010; Santos, Abreu, Costa, Boahid \& Pereira, 2012; Bassinello, 2017).

Além da experiência da alteridade, para Soifer (2005), Souza (2010), e Sebrae-SP (2017), o turismo envolve focos diferentes que a cada ano podem variar de acordo com os desejos dos visitantes. Assim, praias, montanhas, cidades, cultura, história, festas típicas e gastronomia são alguns dos elementos apontados como determinantes ao objetivo de visitação dos turistas, os quais também passam a combinar muitas vezes a realização dessas atividades em conjunto. Nesse sentido, entende-se que o turismo possui uma dinâmica própria, movimentando significativamente a cultura e a economia de determinado local, influenciando setores econômicos e também sociais (Becker, 2014; Carvalho \& Viana, 2014; Silva, Chagas \& Marques Junior, 2016).

É justamente nesse ponto que o turismo começa a produzir seus resultados, como a circulação da moeda, o aumento do consumo de bens e serviços, o aumento da oferta de empregos, a elevação do nível social 
da população e, ainda, o aparecimento de empresas dedicadas ao setor (agências de viagens, hotéis, restaurantes, transportes, cinemas, etc.)

Por sua vez, esta atividade não pode ser caracterizada apenas como uma ação de visitação a atrativos isolados, tendo em vista que tais atrativos frequentados nos lugares considerados turísticos são munidos de referência histórica, cultural, geográfica, ou até mesmo relacionados ao meio ambiente do lugar, ou seja, ao visitarem lugares turísticos as pessoas passam a ter a oportunidade de vivenciar não apenas uma experiência, mas um conjunto de novas descobertas, novos sentimentos, novas curiosidades, novas vivências (Tavares, 2002; Pezzi \& Santos, 2012; Ramos \& Costa, 2017; Sebrae-SP, 2017). Além disso, cabe destacar, ainda, que nesse contexto o apoio e participação da população residente é de extrema importância para a consolidação da cidade como turística e, por isso, as políticas de gestão e planejamento devem estar de acordo e serem de conhecimento dos moradores locais (Gursoy, Jurowski \& Uysal, 2002; Silva, Chagas \& Marques Junior, 2016).

Muitas cidades brasileiras são caracterizadas pela prática constante do turismo. Como exemplos temos o Rio de Janeiro, Gramado, Curitiba, Salvador, Trancoso, Florianópolis, Fortaleza, Ouro Preto, Caldas Novas, Búzios e Recife. Essa consideração acerca das "cidades turísticas" possibilita que algumas se tornem conhecidas tanto nacionalmente, quanto internacionalmente (Tavares, 2002; Revista Exame, 2013). Para se ter uma ideia, em 2017 o Brasil recebeu mais turistas vindos de outros países (compreendendo um total de 6.588.770 turistas estrangeiros) do que em períodos de eventos como Olimpíada (6.546.696) e Copa do Mundo (6.429.852) (MTur, 2018).

Cabe ressaltar a notoriedade do Brasil em meios de comunicação estrangeiros nos quais o país é considerado destino e atrativo turístico. Como exemplo o Die Welt Grenzenlos [grifo do autor], um renomado programa de 
viagem da Alemanha, que enfatizou as belezas, o potencial, a diversidade e curiosidades do estado do Amazonas no exterior "A reportagem [...] aborda, além das belezas da floresta, o açaí, os botos, rituais indígenas, os rios e também parte da vida cotidiana dos moradores na agitada metrópole Manaus" (Instituto Brasileiro do Turismo [Embratur], 2019). Por sua vez, a participação de estrangeiros em eventos turísticos no Brasil também é evidenciada no contexto do turismo religioso, com destaque para a prática das peregrinações: "[...] nos últimos anos o Brasil tem registrado a presença de peregrinos estrangeiros motivados pelo turismo religioso: em 2017 foram 30 mil visitantes estrangeiros focados na religiosidade e atrativos do Brasil" (FESTURIS Gramado, 2018).

Nesse cenário, a conjuntura das cidades passa a ser transformada no momento que o turismo prevalece como meio de entretenimento e como prática de lazer e consumo e todo o escopo econômico passa a sofrer algum tipo de influência, refletindo em retornos financeiros para as cidades e fortalecendo o desenvolvimento local (Banducci \& Barreto, 2001; Zorzi \& Cerqueira, 2010; Pezzi \& Santos, 2012; Trindade, César \& Vianna, 2019). Essa dinamicidade fica evidente no aumento da demanda pelos setores alimentícios, como restaurantes e bares, no crescimento do setor hoteleiro, no incremento da demanda por transportes, na venda de produtos artesanais, serviços de guias turísticos e/ou intérpretes, entre outros.

Esse nicho de mercado promove um movimento muito interessante de descentralização dos benefícios da atividade turística. Esse fluxo de turistas aquece a economia de destinos de pequeno e médio porte e promove a geração de renda em regiões descoladas de grandes capitais. Aí está o grande valor do turismo: uma atividade com alta capacidade de geração de empregos, que distribui desenvolvimento (MTur, 2018).

Em conformidade, Guillaumon (2011) expõe que o turismo pode ser compreendido como uma atividade econômica que estimula o desenvolvimento territorial, com destaque para aquele que lida com 
riquezas naturais e culturais, bem como com populações de baixa renda. Assim, o turismo é colocado em prática com o intuito de auxiliar empreendimentos que visem o crescimento da cidade e que, ao mesmo tempo, sejam fontes geradoras de oportunidades de trabalho para a população.

No entanto, mesmo sendo evidentes os aspectos positivos decorrentes da prática turística, cabe destacar o posicionamento de alguns autores ao defenderem que as mudanças advindas do turismo podem gerar, também, transformações negativas onde este se insere.

Por sua vez, os impactos negativos podem ser observados com exclusividade em favorecimento de algumas classes sociais, o que prejudica a população corroborando para a existência e aguçamento de desigualdades. Além disso, outro elemento conflitante corresponde à substituição das atividades tradicionais, impactando na própria cultura do lugar, abolindo a possibilidade em manter uma tradição de atividades passadas de geração para geração. Por fim, os autores ainda versam sobre o risco ao qual fica exposto o meio ambiente natural e físico do lugar turístico, já que este pode ser afetado por turistas que não compreendem a importância da preservação e manutenção da sustentabilidade do local visitado (Besculides, Lee \& McCormic, 2002; Brida, Osti \& Barquet, 2010; Díaz \& Gutiérrez, 2010; Silva, Chagas \& Marques Junior, 2016; Grimm, Alcântara \& Sampaio, 2018).

Por sua vez, essa conotação é evidenciada por Santos (2010), em que, a partir de uma análise do livro "Turismo e Geografia: abordagens críticas", esta elucida a contradição acerca do turismo como sendo motor de desenvolvimento e, ao mesmo tempo, um elemento de promoção de disparidades sociais. Apesar do turismo contribuir para a movimentação e ascensão da atividade econômica na região, a partir da exploração de recursos naturais e histórico-culturais, ele pode gerar concentração de 
capital, privilegiando certas pessoas em detrimento de outras. Não obstante, considerando as peculiaridades e intensidade do turismo, este também pode impactar na organização espacial, influenciando, de maneira díspar, na constituição dos territórios, como é o caso do turismo religioso versus turismo de negócios.

Dias (2008) também corrobora com o pensamento da existência de duas vertentes do turismo - a positiva e a negativa. Para o autor, o fluxo constante de pessoas viajando ao redor do mundo influencia diretamente a economia, uma vez que modifica as estruturas de trabalho, faz com que certos empreendimentos sejam criados e outros desativados, além de alterar, de forma assídua, diversos setores, como o de transporte, entretenimento e obras públicas. Toda essa conjuntura de transformações recai sobre a sociedade na forma de geração e distribuição de renda, fazendo com que determinados segmentos sejam impactados pela atividade turística, principalmente no que se refere aos produtos criados para atender aos turistas, o que contribui para a expansão de novos setores econômicos.

Não obstante, o impacto que o grande número de visitantes pode provocar nas cidades se torna evidente e traz à tona a preocupação com a cultura e a tradição dos lugares, além da preservação ecológica das regiões: "Esse fluxo de viajantes provoca mudanças econômicas, sociais, culturais e ambientais significativas que, se não bem dimensionadas, podem tornar o turismo um problema para as comunidades receptoras, provocando a destruição de modos de vida tradicionais e de regiões ecologicamente preservadas"(Dias, 2008, p. 16). Todavia, apesar desses apontamentos, não se pode negligenciar a importância do turismo e de sua dimensão para a promoção das mudanças na conjuntura das cidades, o que o torna um instrumento valoroso, já que "(...) modifica, transforma, revigora os espaços, territorializa outros e cria inúmeras redes e fluxos de comunicação e pessoas" 
(Santos, 2010, p. 132).

Oliveira e Guerra (2016), ao refletirem sobre as mudanças ocasionadas nos espaços urbanos, evidenciam a forte ligação que se estabelece entre a economia e a cultura, repercutindo em questões estratégicas e políticas das próprias cidades.

[...] hoje vivemos num contexto marcado pela globalização e pela intensificação da competição interurbana [...]. Estamos, pois, perante uma lógica de diferenciação, que surge como consequência do processo de globalização, sendo que neste jogo competitivo, as cidades se veem compelidas a identificar um factor distintivo, uma marca de autenticidade, que as coloque numa boa posição no sistema mundial. [...] as cidades competem, procurando diferenciar-se umas das outras [...] apostam cada vez mais no património e na cultura de modo a conquistar e reforçar a sua atractividade e competitividade territorial, contribuindo assim para a consolidação de uma lógica de culturalização da vida urbana (Oliveira \& Guerra, 2016, p. 119).

A partir do exposto, é possível compreender que a globalização exerce uma forte influência sobre a dinâmica das cidades e essa interferência se mostra, principalmente, quando se aborda a dimensão cultural, o que intensifica a competição por diferenciação e autenticidade no espaço urbano (Montanari \& Giraldi, 2013). Por sua vez, essas transformações resultam no contexto turístico de cada localidade, sendo um atrativo para aqueles que buscam alguma forma de lazer ou até mesmo um mecanismo de lucratividade para aqueles que pretendem investir em algum empreendimento.

Em conformidade, essa concorrência turística que se estabelece também é evidenciada nos trabalhos de Portuguez e Teubner (2001, p. 80), os quais apontam que

a competência turística de uma localidade é vista atualmente a partir não somente de seus atrativos e potencialidades, mas, sobretudo, de sua capacidade de seduzir [grifo do autor] e, principalmente, agradar uma clientela cada dia mais exigente e sedenta de novidades. Assim, sempre que se diversifica a oferta recreativa dos lugares turísticos, criase a expectativa do reconhecimento dos esforços 
empreendidos e a aquisição de viagens a eles destinadas.

Nesse aspecto, Montanari \& Giraldi (2013) e Mazaro (2017) versam sobre a importância do estabelecimento de estratégias que corroboram na disseminação de uma imagem atrativa do lugar e assinalam, nesse contexto, sobre a utilização de critérios de sustentabilidade e inovação como sendo mecanismos de vantagem competitiva e criação de valor.

Dessa forma, a partir do exposto, é possível compreender que o turismo passa a ser um elemento de caracterização e destaque urbanístico, sendo, por isso, tão importante evidenciar o papel do marketing turístico e suas peculiaridades na construção da imagem e promoção das cidades.

\section{MARKETING TURÍSTICO: UMA FORMA DE PROMOÇÃO DAS CIDADES}

A abordagem do marketing turístico pode ser entendida como uma filosofia de trabalho por meio da qual as organizações, públicas ou privados, destinam esforços para a captação e manutenção expressiva de turistas, a partir da execução de determinadas atividades no mercado. Assim, quando se fala em marketing turístico, há o estabelecimento de uma interrelação entre associações do setor de turismo, transporte, hotéis, agências de viagens, restaurantes e a interação com a própria comunidade (Filho, 2001).

Em consonância ao exposto, Zozi e Cerqueira (2010), Mota (2011), e Pezzi e Santos (2012) argumentam que o marketing turístico se encontra diretamente relacionado à atuação das organizações e cidades na tentativa de consolidarem seus espaços como destinos escolhidos por turistas, sendo estas localidades vistas como um diferencial munido de atratividade. Nesse sentido, o marketing turístico se constitui na promoção de um destino ou empreendimento, criando no mercado uma imagem de destaque desses lugares, possibilitando, assim, sua comercialização como destino turístico.

Por sua vez, este escopo abrange o mercado de turismo e hotelaria de maneira holística, com a mesma atenção que é destinada aos 
produtos e serviços que constituem esse contexto de oferta, sendo consideradas todas as características do mercado - impactos socioeconômicos, ecológicos, culturais -, e toda sua complexidade. Dessa forma, considerando esta conjuntura, um dos elementos primordiais para a ascensão de uma cidade, enquanto destino turístico, é a forma como a comunicação nela é elaborada e praticada, possibilitando sua divulgação e promoção (Mota, 2011 ; Mazaro, 2017).

Essa relevância da comunicação é defendida nos estudos de Tineu e Fragoso (2010), ao destacarem a importância desse elemento, principalmente para a formulação estratégia de apresentação das cidades no mundo:

A detecção e a compreensão dos processos de comunicação na atividade turística são de fundamental importância para o estabelecimento de estratégias de comunicação e marketing das empresas turísticas e também das destinações turísticas, sob o ponto de vista da autoridade pública e dos órgãos responsáveis por todas as atividades turísticas e de lazer, os equipamentos, o meio ambiente e os agentes turísticos de uma determinada localidade (Tineu \& Fragoso, 2010, p. 117).

Montanari e Giraldi (2013), e Mazaro (2017), corroboram com essa explanação ao afirmarem que o marketing turístico possui uma relação direta com a formulação das estratégias de mercado e as diversas ações realizadas, tendo por finalidade a captação e manutenção de visitantes.

Nesse sentido, Filho (2001) apresenta os principais elementos que devem ser considerados na determinação das estratégias de atuação mercadológica, as quais são evidenciadas em doze passos: $1^{\circ}$ ) Conscientização turística - relacionada ao quanto as autoridades, políticos, empresários e a própria população, percebem a importância da prática turística para a cidade, beneficiando não somente os visitantes, mas também melhorando a qualidade de vida dos habitantes de uma região, a partir de investimentos estruturais como saneamento, tratamento de água e energia elétrica, estradas, aeroportos e outros; $2^{\circ}$ ) Criação de um 
órgão oficial de turismo - ou seja, uma entidade que tenha como enfoque o papel de coordenar e definir a política turística da cidade, com formação de parcerias, incremento de iniciativas empresariais, e desenvolvimento de ações para atração turística; $3^{\circ}$ ) Dotação orçamentária - relacionada ao quanto os setores público e privado estão dispostos a investimentos turísticos, destinando os recursos necessários para a consolidação e promoção da cidade como um destino de viagem, promovendo a geração de receitas a partir da relação custo-benefício; $4^{\circ}$ ) Preparação de recursos humanos relacionado à capacitação e qualificação com que os profissionais das cidades turísticas (taxistas, guias turísticos, garçons, recepcionistas, dentre outros), estão preparados em termos de atendimento e tratamento aos visitantes, tendo em vista que tais posicionamentos influenciará diretamente na imagem que o turista construirá da cidade, refletindo no pós-venda do produto turístico; $5^{\circ}$ ) Elaboração de um calendário de eventos turísticos - o que possibilita a criação de um banco de dados que auxilie no direcionamento dos próprios segmentos de mercado da cidade, promovendo a adoção eficaz de estratégias de comunicação e de outras ações mercadológicas; 6) Guia básico de informações turísticas - esta estratégia defende sobre a importância da disponibilização e disseminação de informações úteis para os turistas como endereços, lugares onde ir, como ir, informações sobre o local visitado e sua respectiva geografia, cultura, história, enfim, todas as informações que fazem parte da experiência turística do visitante; $7^{\circ}$ ) Delimitação do roteiro turístico - diz respeito ao quanto é importante estipular determinados horários para a experimentação das diversas atrações turísticas, equilibrando sempre o limite entre a curiosidade e a chatice da atividade realizada; $8^{\circ}$ ) Sinalização turística - ou seja, uma forma de oferecer informações por meio de sinalização, beneficiando tanto turistas quanto moradores acerca dos lugares a serem visitados, possibilitando o entendimento do visitante sobre qual o deslocamento a ser feito, sem que seja necessário aderir ao guia turístico, uma vez que 
a informação está visualmente clara e objetiva; $9^{\circ}$ ) Defesa do meio ambiente - relacionado ao cuidado, respeito e valorização do meio ambiente da cidade, sendo esta uma tarefa de todos os envolvidos nessa conjuntura (poder público, população, e turistas); $10^{\circ}$ ) Liberação do horário comercial - engloba os direitos trabalhistas acerca dos horários de serviços, e a respectiva composição dos interesses dos visitantes e servidores; $11^{\circ}$ ) Promoção e divulgação nos polos emissores - está relacionado à promoção e divulgação das cidades turísticas na mídia, a partir do emprego de estratégias nos mercados emissores, o que demanda criatividade e investimento correto de recursos; e $12^{\circ}$ ) Estatísticas para análises dos resultados - a oportunidade de obter um feedback das experiências vivenciadas pelos turistas em todos os aspectos da viagem, possibilitando que, a partir do acesso a essas informações, sejam elaboradas novas ações de melhoria dos serviços turísticos da cidade. Concomitantemente ao exposto, o autor ainda inclui mais um último elemento estratégico, sendo este a ampliação dos espaços e o desenvolvimento de novos produtos, ou seja, a permanente renovação de atrativos turísticos e a manutenção daqueles considerados como tradicionais.

Ainda nessa abordagem do marketing turístico, Flores, Cavalcante \& Raye (2012) apontam que este escopo compreende características próprias e especiais dos serviços de viagem e turismo oferecidos no mercado local, e ainda ressaltam que tais serviços devem ser adaptados de acordo com a realidade de cada setor, fazendo com que os princípios padrões de marketing estejam sempre alinhados com a conjuntura de cada lugar turístico. Nunes e Platt (2012) corroboram com esse pensamento ao apontarem em seus estudos a sazonalidade como uma das peculiaridades do marketing turístico e, por isso, versam sobre a importância de se entender a dinâmica turística de cada cidade.

Um problema muito comum em lugares em que a economia é baseada na atividade turística é a sazonalidade, ou seja, restrita a 
determinada estação do ano. A economia local sofre forte oscilação que, se não administrada de maneira correta, pode ocasionar perdas econômicas e até falência de empreendimentos não preparados. (Nunes \& Platt, 2012, p. 203).

Ao explorarem o marketing turístico, Aguiar, Silva, Gandara e Souza (2011) consideram a cidade como sendo uma grande obra de arte, ao ressaltarem que esta é, ao mesmo tempo, uma construção do simbólico e um instrumento material da vida em comunidade, refletindo a cultura, as vivências e, portanto, a identidade de um povo. E é justamente esse conjunto de originalidade, identidade e características que despertam e acentuam os interesses dos visitantes em conhecerem a cidade, promovendo-a e consolidando-a como um lugar turístico. Nesse aspecto, o marketing turístico auxilia na projeção, valorização e execução de produtos que visem à satisfação das necessidades relacionadas à viagem.

César e Vianna (2015) discorrem a temática versando sobre a existência de atrativos turísticos nas cidades, identificados em objetos, lugares ou ações, sendo elementos de valorização e que repercute em incentivos à visitação de turistas. Por sua vez, atrativos turísticos são entendidos como uma construção social, refletidos nas esferas culturais, religiosas e econômicas que tem como principal caraterística a diversidade de possibilidades de visitação. Dessa forma, uma mesma cidade que contemple vários lugares considerados como atrativos turísticos, passa a ter maior representatividade no mercado e, consequentemente, maior interesse por parte de visitantes que almejem vivenciar novas experiências.

Por sua vez, nessa conjuntura, os registros fotográficos passam a ser elementos importantes para a promoção e divulgação dos lugares turísticos, impactando diretamente na imagem produzida da cidade. É a partir das fotografias e postagens em sites e redes sociais que características e valores dos atributos turísticos são comunicados, permitindo uma construção visual do destino a ser escolhido (Dopra, Trzaskos \& Baum, 2011; Boley, Magnini \& 
Tuten, 2013).

Moretti, Bertoli e Zucco (2016) corroboram com essa afirmativa ao ressaltarem a importância da disseminação de informações acerca do local turístico, sendo este um fator de forte influência para a consolidação da imagem do lugar na mídia. Nesse sentido, a utilização da internet, por exemplo, passa a ser o principal meio de obtenção de informações para estrangeiros que pretendem realizar passeios turísticos, buscando, assim, informações sobre hospedagem, transporte internacional, atrativos e passeios existentes, ou até mesmo pela visualização de fotos postadas por pessoas em redes sociais. "A Internet foi a principal fonte de consulta dos visitantes internacionais que estiveram no Brasil em 2015, sendo utilizada por 44\% dos turistas." (Ministério do Turismo, 2016).

A partir do exposto é possível compreender que o marketing turístico, quando trabalhado de forma correta, produz resultados que refletem na volta do turista à cidade, ou até mesmo na indicação do local visitado por ele a outras pessoas que almejam uma inesquecível experiência. Por sua vez, essa prática do marketing turístico também deve ser considerada no contexto do turismo religioso, o qual, apesar de ter como essência a religiosidade, engloba atividades e atrativos turísticos que culminam em transformações que refletem em desenvolvimento local onde essa prática é realizada.

\section{TURISMO RELIGIOSO E DESENVOLVIMENTO LOCAL}

Movimentando um número cada vez maior de pessoas, o turismo religioso pode ser considerado como fator gerador de economia, emprego e renda nas cidades em que este tipo de atividade é praticado (Carvalho \& Viana, 2014). Por sua vez, essa configuração é evidenciada pelo Jornal de Turismo (2015), destacando que as viagens religiosas estão crescendo a cada ano de forma significativa, possibilitando a geração de empregos para as populações das localidades e movimentando a 
economia, tendo em vista que os viajantes e turistas passam a investir e consumir os produtos que são oferecidos nesse contexto religioso.

Nesse aspecto, pode-se inferir que o turismo religioso reflete em transformações consideráveis no espaço urbano e essas mudanças podem ser visualizadas na própria estrutura das cidades, as quais passam a ser modificadas para atender a um público específico, a partir do aumento da oferta de serviços diversos modificando, assim, a dinâmica local como um todo.

O comércio passa, então, a contar com um maior número de lojas que vendem artigos religiosos, como também passa a oferecer outros tipos de produtos, tendo em vista que os turistas muitas vezes acabam adquirindo artigos que não sejam apenas de cunho religioso, como roupas, sapatos, acessórios, artigos domésticos e produtos eletrônicos.

Em conformidade com o exposto, Silveira (2007), Jaluska e Junqueira (2012) e Ardigó, Caetano e Damo (2016) ressaltam a influência do turismo religioso nas cidades, destacando as atividades socioeconômicas que este envolve, quais sejam: as agências de viagem de turismo religioso, agências de viagens em geral, transporte aéreo e rodoviário, sistemas de hospedagem, incluindo casas de aluguel para temporada, artesanato de artigos religiosos, indústrias de itens religiosos, comércio local em geral, bem como serviços de apoio (aluguel de carros e diversão).

Assim posto, fica evidente a importância do turismo religioso para uma determinada localidade, uma vez que este movimenta, de forma significativa, todo o complexo das cidades, proporcionando maior rentabilidade e transformações para o desenvolvimento do espaço urbano. Por sua vez, estas mudanças podem ser observadas em Aparecida, como divulgado pelo Jornal de Turismo (2015):

A importância do turismo religioso em Aparecida é tão grande que a própria cidade se desenvolveu por causa da história da imagem de Nossa Senhora da Conceição Aparecida, encontrada por 
pescadores no Rio Paraíba do Sul, em 1917. Os primeiros moradores da localidade, que pertencia à cidade de Guaratinguetá, construíram uma capela para a imagem em 1745 e, com o grande fluxo de fiéis e o desenvolvimento local, Aparecida se desmembrou e passou a ser uma cidade em 1928. [...] A estrutura para receber os turistas é tão bem preparada, que o Santuário possui até mesmo um hotel próprio: o Hotel Rainha do Brasil.

Além disso, ao abordar o turismo religioso, Oliveira (2008) defende tratar-se de um turismo que detém todos os tipos de públicos, ou seja, não de um turismo do qual participam apenas religiosos e devotos. O turismo religioso se torna, ao mesmo tempo, uma forma de praticar o turismo em seu contexto geral, como também uma maneira de manifestar, de forma assídua, a religiosidade contemporânea em diversas sociedades, como a realização das peregrinações e romarias (Jaluska \& Junqueira, 2012; Ardigó, Caetano \& Damo (2016).

A partir dessas considerações, pode-se inferir que o turismo religioso implica em mudanças consideráveis no espaço urbano, pois movimenta toda a conjuntura social, política e econômica da cidade. Essa dinâmica, por sua vez, se reflete nas estruturas espaciais de cada localidade, como o aumento das construções de igrejas e capelas, as quais passam a ter um número maior justamente para atender a um público que cresce consideravelmente a cada ano. Tais construções interferem e modificam a paisagem local, além de abrir possibilidades para o surgimento de novos empregos no setor de construção civil e na resultante demanda por produtos necessários para a realização das obras.

Com destaque para o comércio no contexto do turismo religioso, este passa a apresentar mudanças significativas que interferem, inclusive, no próprio desenvolvimento local. Essa realidade se faz presente, ao passo em que há maior demanda pelos produtos e serviços que são oferecidos e, nesse contexto, o setor hoteleiro consiste em um dos principais elementos geradores de emprego e renda, mobilizando o escopo financeiro da 
cidade, principalmente em alta temporada das festas religiosas católicas.

Vale ressaltar que nesta conjuntura também cresce a demanda por aluguéis de casas para temporada. A exemplo da Festa do Divino Pai Eterno que ocorre em Trindade/GO, a qual acontece nos meses de junho e julho (anualmente), muitas famílias alugam suas casas para visitantes e turistas que passam a investir determinado valor financeiro para delas usufruir nos respectivos dias de festa. Assim, verifica-se que o turismo religioso resulta em rendimentos para a própria população da cidade, que enxerga oportunidades para se obter determinada renda.

A partir do exposto, é possível compreender que o turismo religioso implica em transformações significativas e profundas mudanças nos espaços urbanos, resultando em maior rentabilidade para as cidades, aumento do comércio em geral e, ao mesmo tempo, possibilitando que as cidades se tornem conhecidas, tanto nacional como mundialmente, pelo turismo religioso que nelas é praticado. Por sua vez, estas mudanças são possíveis de serem verificadas na própria paisagem, a qual se modifica conforme o aumento das construções que passam a se consolidar como elemento turístico, ou mesmo para atender à demanda do comércio vigente.

\section{TURISMO RELIGIOSO: A ABORDAGEM DAS FESTAS CATÓLICAS}

O turismo religioso se caracteriza por ser uma atividade turística que envolve a dimensão da fé. Assim, no turismo religioso é a fé que conduz as pessoas à ação de se deslocarem de seus habitats de vida em busca de experiências religiosas e também espirituais. Tais experiências podem ser vivenciadas de variadas formas, como a participação dos indivíduos em missas, visitações em templos e santuários, shows católicos, o que possibilita o conhecimento de novas culturas religiosas ou, até a prática de rituais e participação em eventos religiosos realizados em determinada localidade (Maio, 2004; Jaluska \& Junqueira, 2012). 
Nesse contexto, as festas religiosas católicas podem ser entendidas como as atividades sagradas realizadas em momentos únicos que representam o momento de intimidade e experiência de religiosidade e devoção a determinado santo. Dessa forma, podem ser compreendidas como as manifestações de fé, demonstradas e vivenciadas durante as festividades sagradas.

Todavia, cabe destacar, ainda, que as diversas motivações que levam as pessoas a visitar os lugares santos e participar das festividades, correspondem a um grande desafio de gestão para os representantes religiosos, uma vez que nem sempre as pessoas vão em busca apenas de uma experiência religiosa. A explicação para tal ocorrência pode estar relacionada à oferta dos mais variados produtos e serviços oferecidos durante as festanças católicas, os quais nem sempre estão associados à religião, como artigos eletrônicos e itens domésticos (Drule, Chis, Bacila, \& Ciornea, 2012).

Em se tratando das festividades religiosas católicas no Brasil, além das comemorações em Aparecida, podem ser destacadas a festa no Santuário da Beata Irmã Dulce dos Pobres (Salvador/BA), as festas com referência a Padre Cícero (Juazeiro do Norte/CE), as comemorações no Santuário Basílica do Divino Pai Eterno (Trindade/GO), as festas no Santuário de Santa Paulina (Nova Trento/SC), além das festas de São João no Nordeste do país, contribuindo, assim, para a disseminação e no crescimento do turismo religioso.

Para Serrallonga e Hakobyan (2011), a atividade turística religiosa é um segmento de mercado que se encontra em considerável ascensão. Nessa conjuntura, os destinos mais procurados são aqueles que se destacam como lugares santos ou sagrados. São esses lugares que exprimem, em sua concretude a devoção, a peregrinação, sendo dotados de significados e historicidade cultural. Assim, o turismo religioso é caracterizado por ser um 
campo de entendimento complexo, em decorrência dos vários elementos que ele compreende - religiosos, cultura, paisagismo, tradicionalidades, entre outros -, e dos diversos propósitos que levam as pessoas a visitar tais lugares. Por sua vez, essa complexidade também é evidenciada por Schneider e Santos (2015, p. 329), ao considerarem o turismo religioso "como um fenômeno múltiplo, de caráter complexo, abrangendo diferentes significados e motivações, podendo ser analisado e compreendido por meio de abordagens diversas".

Cabe salientar, ainda, que o turismo religioso se configura também pela predominância da prática da peregrinação por parte dos fiéis em eventos festivos católicos. Tal prática corrobora para $\bigcirc$ aumento considerável no número de turistas e devotos a visitarem as cidades em que a presença da religiosidade é constante e onde os espaços destinados às peregrinações já são definidos. Dessa forma, torna-se importante compreender as peculiaridades acerca da peregrinação e entender como esta prática religiosa contribui para o desenvolvimento da cidade.

\section{O PAPEL DA PEREGRINAÇÃo COMO ELEMENTO DE DESENVOLVIMENTO DAS CIDADES-SANTUÁRIO}

Ao abordar a temática da peregrinação, Rosendahl (1996), a partir das contribuições de França (1972), apresenta a abordagem acerca das "cidades de função religiosa". Tais cidades constituem-se, na maioria das vezes, locais de pequeno e médio porte, porém caracterizados por um grande número de devotos que se deslocam para alcançar satisfação espiritual ou para vivenciar os rituais praticados em grandes comemorações festivas religiosas.

Trata-se, portanto, de cidades que possuem uma ordem espiritual predominante e marcadas pela prática religiosa da peregrinação ou romaria ao lugar sagrado. [...] Romaria ou peregrinação [...] é uma prática religiosa que consiste em uma visita na qual o visitante tem uma nítida intenção de devoção. Essa visita é feita a um lugar sagrado e vem acompanhada do comportamento religioso de pedir graças ou 
de agradecimento por uma graça obtida (Rosendahl, 1996, p. 46 e 47).

O local onde acontece a peregrinação pode ser considerado um espaço sagrado, pois nele predomina a presença de simbologias, significados e representações. Assim, pode ser entendido como o local destinado ao fluxo de fiéis para a realização de procissões e o cumprimento de promessas, como pode ser observado na Figura 1, a qual retrata a romaria dos fiéis com destino à cidade de Trindade, localizada no Estado de Goiás, durante a festa em honra ao Divino Pai Eterno. Nesse contexto, os lugares sagrados de ocorrência da peregrinação fazem com que as cidades sejam conhecidas por cidades-santuário ou hierópolis, em outras palavras, locais onde as práticas e crenças religiosas se emanam, criando os centros de convergência de devoções (Rosendahl, 2008).

Figura 1 - Romeiros com destino ao centro de Trindade (Goiás) durante a festa em honra ao Divino Pai Eterno

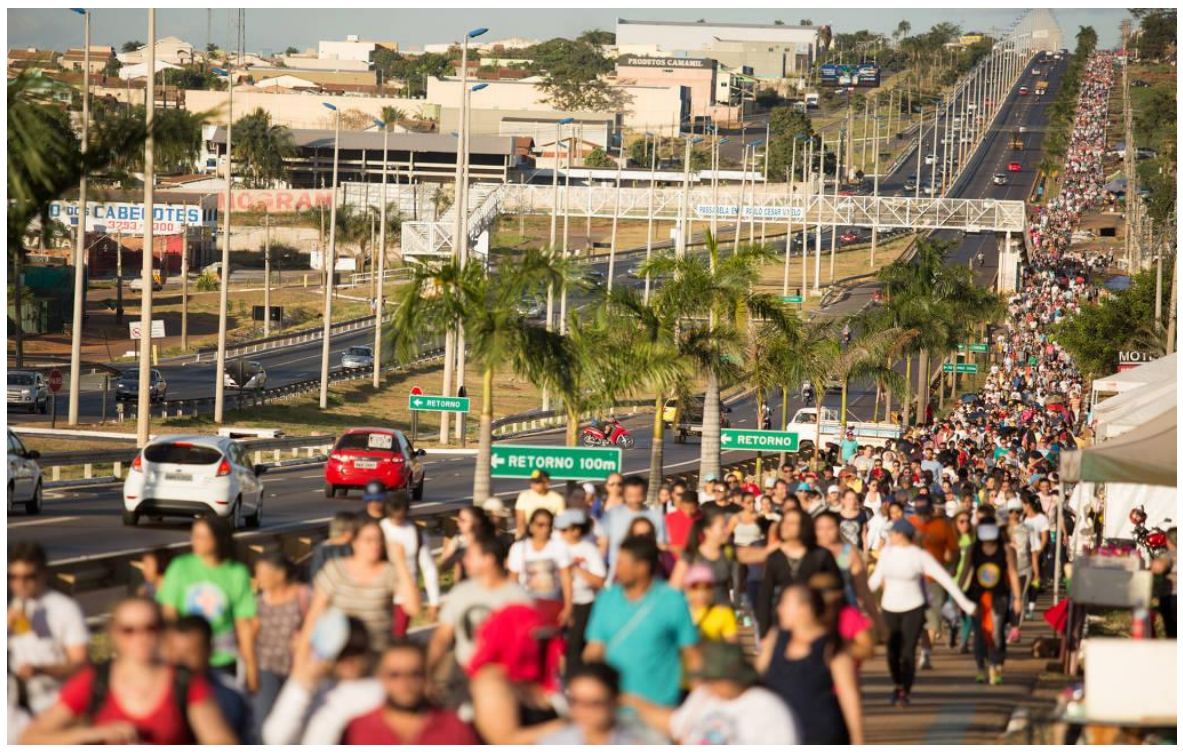

Fonte: Jornal Folha de São Paulo (2018)

Em consonância ao exposto, o ato da peregrinação passa também a ser configurado como um fator de desenvolvimento das cidades-santuário. Esse desenvolvimento vai sendo configurado ao passo que os lugares destinados à realização da caminhada do peregrino são munidos 
não só de sacralidade e da prática de atividades voluntárias mas, também, constituídos de atividades relacionadas à geração de renda, como a venda de artigos religiosos, produtos esportivos, além da constante presença do setor alimentício.

Geralmente as romarias se caracterizam pela prática de uma longa jornada de caminhada e durante a peregrinação os fiéis passam a estar expostos à oferta de produtos, sendo muitas vezes influenciados a fazer compras no decorrer do próprio percurso, seja para adquirir um objeto como lembrança daquele momento da peregrinação, seja para ajudar entidades que comercializam produtos em prol de alguma causa social, ou até mesmo comprar alimentos para que, assim, estejam aptos fisicamente para concluir com êxito a romaria. Esta realidade é demonstrada na Figura 2 que retrata muitos comerciantes que instalam suas barracas para oferecer diversos produtos aos peregrinos durante o percurso da caminhada, os quais contemplam, além de alimentos, a comercialização de artigos religiosos, vestuário e artigos domésticos.

Figura 2 - Barracas na rodovia dos romeiros com destino à Trindade (Goiás) durante a festa em honra ao Divino Pai Eterno

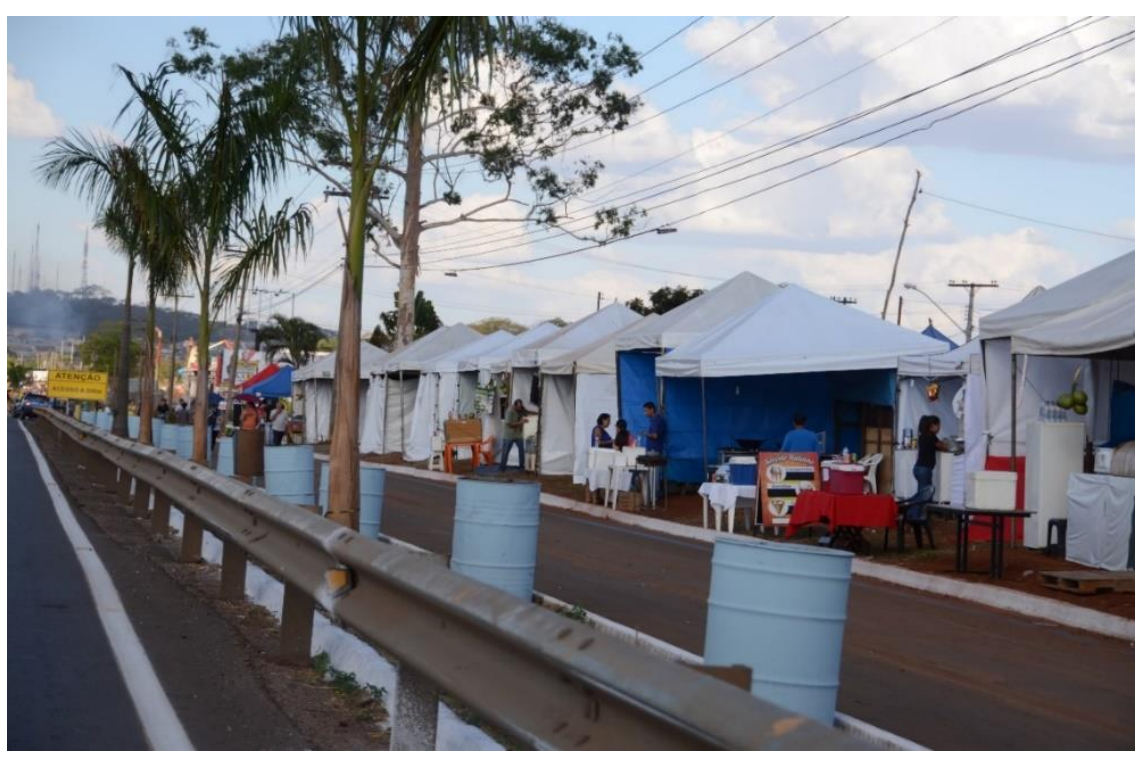


Fonte: Agência Goiana de Infraestrutura e Transportes (GOINFRA) (2018)

Cabe considerar, ainda, que nesse momento da peregrinação muitas empresas utilizam o espaço da romaria para divulgarem suas marcas a fim de que se tornem conhecidas, uma vez que as peregrinações são realizadas com a participação de um número significativo de pessoas. Assim, é possível inferir que a própria atividade da peregrinação corrobora o desenvolvimento das cidades, uma vez que atrai muitos devotos à realização da romaria e, consequentemente, ganha espaço para a oferta e comercialização de produtos, gerando emprego e renda para a própria população da cidade.

Por sua vez, a peregrinação é um fator de oportunidades, ao passo que ao ter a presença de pessoas oriundas de múltiplos lugares, as empresas locais passam a ter a possibilidade de aumentar sua fatia de mercado, sendo possível a criação e estruturação de novos elos mercadológicos que visem à atuação dessas empresas em novos cenários de comercialização que extrapolem os limites atuais locais.

\section{CONSIDERAÇÕES FINAIS}

Este ensaio teórico teve como objetivo incitar uma reflexão acerca da relação existente entre o turismo religioso e suas implicações no espaço urbano, explorando a conjuntura religiosa como um mecanismo de transformação e um meio de divulgação das cidades. Ao mesmo tempo, este estudo apresentou alguns questionamentos acerca da prática turística, a partir da exposição de elementos que instigassem o leitor a analisar o turismo a partir de duas óticas: a primeira, evidenciando o turismo como fonte de desenvolvimento e mecanismo gerador de emprego e renda; e a segunda, versando sobre os impactos negativos que a prática turística pode acarretar à população, seja no favorecimento às desigualdades ou na extinção da cultura tradicional local.

Nesse contexto, ao explorar o turismo como fonte de 
desenvolvimento das cidades, foi possível verificar que este possui dinâmica própria, movimentando e influenciando vários setores econômicos e também sociais. Por sua vez, a conjuntura das cidades passa a ser transformada ao passo que o turismo prevalece como meio de entretenimento e como prática de lazer e consumo e, nesse aspecto, fica evidente a importância da participação e o envolvimento da população na construção da imagem turística do local e da sua consequente manutenção como cidade turística.

O estudo também elucida o papel do marketing turístico para a promoção, divulgação e consolidação da imagem das cidades como destinos turísticos, no âmbito nacional ou internacional, ressaltando que as estratégias a serem aplicadas devem estar de acordo com os objetivos estabelecidos, o que conduz a vantagens competitivas. Nesse escopo, o estudo ressalta a utilização de critérios de sustentabilidade e inovação como sendo mecanismos de vantagem competitiva e criação de valor, sendo identificados como elementos de atratividade das cidades.

Com destaque para o turismo religioso, verificou-se sua influência no espaço urbano, sendo este entendido como uma atividade de forte representatividade econômica, que possui como princípio fundamental a fé, movimentando um número cada vez maior de pessoas por todo o país, principalmente a partir da prática das festas religiosas católicas, acarretando em consideráveis transformações políticas, sociais, econômicas e culturais nos locais em que o turismo religioso é praticado. Por sua vez, essas mudanças podem ser visualizadas na própria estrutura das cidades, as quais são transformadas para atender a um público específico, modificando, assim, a dinâmica local como um todo. Nesse contexto, grandes modificações acontecem no comércio, o qual passa a contar com maior número de lojas que vendem artigos religiosos, como também passa a ofertar produtos diversos, como roupas, sapatos, acessórios, artigos 
domésticos, produtos eletrônicos, dentre outros.

Muitas são as atividades decorrentes da prática do turismo religioso, a saber: as agências de viagem de turismo religioso, agências de viagens em geral, transporte aéreo e rodoviário, sistemas de hospedagem, incluindo casas de aluguel para temporada, artesanato de artigos religiosos, indústrias de itens religiosos, comércio local em geral, bem como serviços de apoio (aluguel de carros e diversão). Em adição, essa dinâmica de transformação se reflete nas estruturas espaciais de cada localidade, como - aumento das construções de igrejas e capelas, justamente para conseguir atender a um público que cresce consideravelmente a cada ano. Nesse sentido, tais construções interferem e modificam a paisagem local, além de abrir possibilidades para o surgimento de novos empregos.

Corroborando com o exposto, foi possível compreender a conceituação das cidades-santuário (ou hierópolis) e como estas estão intimamente interligadas à prática da peregrinação. Por sua vez, neste estudo, a romaria se apresenta, também, como um fator de desenvolvimento das cidades-santuário, ao passo que atrai grande número de devotos que participam do ato religioso como uma forma de pedir graças ou agradecer por aquelas que foram recebidas em devoção. Assim, constatou-se que a peregrinação abre caminhos de oportunidades de geração de emprego e renda, além de potencializar a construção de elos de mercado local, regional ou nacional.

A partir deste estudo, é possível compreender as peculiaridades e a importância do turismo religioso como fonte geradora de desenvolvimento das cidades, bem como seu papel na dimensão cultural e econômica do país. A partir dos resultantes fundamentados neste trabalho, ficam evidentes as transformações que se desencadeiam na dinâmica das cidades, e em suas conjunturas, a partir da prática turística religiosa, contribuindo de forma significativa para o desenvolvimento local. Assim posto, este estudo 
corrobora a exploração da temática e progride, assim, no campo de pesquisas em turismo e áreas afins.

Contudo, espera-se que a partir das discussões e pontos de vista apresentados no decorrer deste trabalho, seja possível aos leitores a construção de uma reflexão que responda aos questionamentos propostos na parte introdutória deste estudo e, mais ainda, que todos os atores que fazem parte da conjuntura das cidades, poder público e privado, e a própria sociedade, repensem e analisem a forma de atuação, os benefícios e os impactos decorrentes da prática turística na vida da população. Como sugestão, propõe-se que novas reflexões sejam instigadas, principalmente no tocante à prática turística religiosa, tão importante de ser explorada no contexto acadêmico científico, inclusive, com a investigação de outras religiões, possibilitando compreender, em maior amplitude, o escopo do turismo religioso brasileiro.

\section{REFERÊNCIAS}

Agência Goiana de Infraestrutura e Transportes. (2018). Barracas na rodovia dos romeiros: mais de 600 inscritos. Goiânia: Goinfra. Recuperado de http://www.agetop.go.gov.br/noticias/Barracas-na-Rodovia-dos-

Romeiros-mais-de-600-inscritos/213094

Aguiar, H., Silva, J. B., Gandara, J. M. G., \& Souza, T. A. (2011). O Marketing Turístico como Instrumento de produção e transformação do espaço de Curitiba e Região Metropolitana. Encontros Científicos - Tourism \& Management Studies, (1), 306-318.

Aragão, I. R. (2015). Turismo étnico e cultural: a coroação da rainha das taieiras como atrativo turístico potencial em Laranjeiras (SE). Caderno Virtual de Turismo, 15(2), 195-210.

Araújo, W. A., Temoteo, J. A. G., Andrade, M. O., \& Trevizan, S. D. P. (2017). Desenvolvimento local, turismo e populações tradicionais: elementos conceituais e apontamentos para reflexão. Revista Interações, 18(4), 518. Recuperado de http://www.scielo.br/pdf/inter/v18n4/1518-7012-inter18-04-0005.pdf. doi. 10.20435/inter.v18i4.1392

Ardigó, C. M., Caetano, L., \& Damo, L. P. (2016). O turismo religioso e o processo de comunicação de marketing: um estudo do Santuário de 
Santa Paulina em Nova Trento - SC. Revista Turismo: Visão e Ação, 18(2), 353-377.

Banducci Jr., A., \& Barreto, M. (2001). Turismo e identidade local: uma visão antropológica. Campinas: Papirus.

Barbosa, F. F. (2005). O turismo como um fator de desenvolvimento local e/ ou regional. Caminhos de Geografia, 10(14), 107-114.

Barbosa, L. G. (2012). The competitiveness of brazilian tourist destinations (Thesis PhD). Nottingham University Business School, Nottingham, United Kingdom. Recovered from http://eprints.nottingham.ac.uk/28978/1/604888.pdf

Barcellos, C. M. (2016). Mobilidade urbana: efeitos causados pelo turismo de massa no município de Cabo Frio (Trabalho de conclusão de curso). Faculdade de Turismo e Hotelaria, Universidade Federal Fluminense, Niterói, RJ, Brasil.

Bassinello, P. Z. (2017). Uma viagem ao encontro do tempo de alteridade no turismo: desmembrando horizontes epistemológicos a partir das contribuições de uma filosofia dialógica da linguagem do Círculo de Bakhtin (Tese de Doutorado). Centro de Educação e Ciências Humanas, Universidade Federal de São Carlos, São Carlos, SP, Brasil. Recuperado de https://repositorio.ufscar.br/bitstream/handle/ufscar/8898/TesePZB.pdf?se quence $=1$ \&isAllowed $=y$

Bastos, S., Salles, M. R. R., \& Bueno, M. S. (2014). Turismo e imigração: por uma política de hospitalidade no Brasil entre 1937 e 1951. Rosa dos Ventos Turismo e Hospitalidade, 6(2), 197-216.

Bazanini, R., \& Giglio, E. M. (2017). The Role of Stakeholders in Solomon'S Temple: An Exploratory Study. Organizações \& Sociedade, 24(83), 674690.

Bazanini, R., \& Machado Junior, C. (2018). O Mercado como Religião: A Dinâmica da Rede de Negócios nos Megatemplos. Brazilian Business Review, 15(3), 262-283.

Becker, E. L. S. (2014). Geografia e Turismo: Uma Introdução ao Estudo de Suas Relações. Rosa dos Ventos: Turismo e Hospitalidade, 6(1), 52-65. Recuperado de http://www.ucs.br/etc/revistas/index.php/rosadosventos/article/view/233 3/pdf_216

Besculides, A., Lee, M., \& McCormick, P. (2002). Residents Perceptions of the 
Cultural Benefits of Tourism. Annals of Tourism Research, 29(2), 303-319.

Boley, B. B., Magnini, V. P., \& Tuten, T. L. (2013). Social media picture posting and souvenir purchasing behavior: Some initial findings. Tourism Management, (37), 27-30.

Borchardt, P., \& Bianco, M. F. (2016). Meanings of Volunteer Work: A Study With Members of a Lutheran Institution. Revista de Administração Mackenzie, 17(5), 61-84.

Borges, A. F., Enoque, A. G., Katrib, C. M. I., \& Gonçalves, L. R. D. (2016). Práticas Organizativas: Um Estudo sobre o Congado na Região do Triângulo Mineiro. Revista Interdisciplinar de Gestão Social, 5(1), 129-151.

Boulhosa, M. S. (2017). Festividade de São Sebastião, de Cachoeira do Arari: Uma Possibilidade para o Desenvolvimento do Turismo Cultural na Ilha do Marajó, Brasil. Revista Hospitalidade, 14(1), 1-15.

Brida, J. B., Osti, L., \& Barquet, A. (2010). Segmenting residents perceptions toward tourism: A cluster analysis with multinomial logit model of a mountain community. International Journal of Tourism Research, 12(5), 591-602.

Camargo, L. O. L. (2019). Hospitalidade, turismo e lazer. RBTUR - Revista Brasileira de Pesquisa em Turismo, 13 (3), 1-15. Recuperado de https://rbtur.org.br/rbtur/article/view/1749. doi. 10.7784/rbtur.v13i3.1749

Carvalho, R. C. O. de. \& Viana, M. dos S. (2014). Somos o que consumimos: aspectos identitários e turismo contemporâneo. Turismo: Visão e Ação, 16(3), 690-709. Recuperado de https://siaiap32.univali.br/seer/index.php/rtva/article/view/7746/4428. doi: 10.14210/rtva.v16n3.p690-709

César, P. A. B., Belusso, A., \& Silva, C. R. (2017). Praça do Centro de Flores da Cunha (RS): Palco de Realizações Sociais, Religiosas e Turísticas. Caderno Virtual de Turismo, 17(1), 123-137.

César, P.A.B., \& Vianna, A. A. (2015). Aparecida: a formação socioespacial do atrativo religioso. Caderno Virtual de Turismo, 15(2), 149-166.

Cordeiro, E. D. (2008). O turismo como fomentador da configuração especial do município de ouro preto: o novo distrito de Lavras Novas. Revista de Cultura e Turismo, 2(2), 1-26.

Curado, J. G. T., \& D'abadia, M. I. V. (2018). Festa de Padroeiros: Cenários de Turismo Religioso no Estado de Goiás (Brasil). Marketing \& Tourism Review, 
$3(3), 1-27$.

Dall'Agnol, S. (2012, novembro). Impactos do turismo x comunidade local. Anais do VII Seminário de Pesquisa em Turismo do Mercosul - Semintur, Turismo e Paisagem: relação complexa. Caxias do Sul, RS, Brasil, 7.

Díaz, R., \& Gutiérrez, D. (2010). La actitud del residente en el destino turístico de Tenerife: evaluación y tendência. PASOS - Revista de Turismo y Patrimonio Cultural, 8(4), 431-444.

Dias, R. (2008). Planejamento do turismo: política e desenvolvimento do turismo no Brasil. São Paulo, SP: Atlas.

Dropa, A. F. N. S., Trzaskos, L., \& Baum, J. (2011, setembro). A imagem fotográfica como recurso de valorização cultural e seu uso pelo turismo: um estudo de caso da Colônia Sutil. Anais do VII ENPPEX - II Seminário de Ciências Sociais Aplicadas da Faculdade Estadual de Ciências e Letras de Campo Mourão. Campo Mourão, PR, Brasil, 7.

Drule, A. M.; Chis, A.; Bacila, M. F.; Ciornea, R. (2012). A new perspective of non-religious motivations of visitors to sacred sites: evidence from Romania. Procedia: Social and Behavioral Sciences, 62, 431-435. Recuperado

de https://www.sciencedirect.com/science/article/pii/S1877042812035112?vi a\%3Dihub. doi: 10.1016/j.sbspro.2012.09.070

Enoque, A. G., Borges, A. F., \& Borges, J. F. (2015). Religião e consumo: aspectos conceituais, limites e possibilidades. Farol - Revista de Estudos Organizacionais e Sociedade, 2(4), 488-532.

(2016). O Sagrado e o Profano nas Organizações Contemporâneas. Revista Pretexto, 17(2), 28-41.

Erig, G. A., Santana, A. G., \& Ferreira, M. C. A. (2018). Turismo e Evento: Festa do Divino Espírito Santo em Natividade, Tocantins, Brasil. Rosa dos Ventos Turismo e Hospitalidade, 10(3), 594-606.

Feira Internacional de Turismo. (2018). Turismo religioso movimenta 15 bilhões de reais por ano no Brasil. Brasil: FESTURIS Gramado. Recuperado de https://www.festurisgramado.com/noticias/turismo-religioso-movimenta15-bilhoes-de-reais-por-ano-no-brasil/

Filho, A. B. (2001). Marketing turístico para o espaço urbano: comentários acadêmicos e profissionais. In Castrogiovanni, A. C. (Org), Turismo urbano. São Paulo: Contexto

Flausino, V. S., Medeiros, C. R. O., \& Valadão Júnior, V. M. (2018). Poder e 
Religião: a Doutrina Espírita no Modo de Pensar dos Gestores de Uberaba/MG. Revista ADM.MADE, 22(1), 58-76.

Flores, L. C. S., Cavalcante, L. S., \& Raye, R. L. (2012). Marketing turístico: estudo sobre o uso da tecnologia da informação e comunicação nas agências de viagens e turismo de Balneário Camboriú (SC, Brasil). Revista Brasileira de Pesquisa em Turismo, 6(3), 322-339.

Frías, C. H. R. (2019). Turismo, Religión y Motivación de Viajes en el Ámbito de las Relaciones entre Cuba y Estados Unidos. Rosa dos Ventos - Turismo e Hospitalidade, 11 (1), 66-83.

Giacomini F., G., \& Pellegrini Filho, A. (1991). Resenha: - Marketing turístico: um enfoque promocional - (RUSCHMANN, Doris van de Meene - 1991) / Sociologia do turismo - (KRIPPENDORF, Jost - 1989). Turismo em Análise, 2(1), 89-91

Grimm, I. J., Alcântara, L., \& Sampaio, C. A. C. (2018). O Turismo no Cenário das Mudanças Climáticas: Impactos, Possibilidades e Desafios. RBTUR Revista Brasileira de Pesquisa em Turismo, 12(3), 1-22. Recuperado de http://www.scielo.br/scielo.php?script=sci_arttext\&pid=S1982-

$61252018000300001 \&$ Ing=pt\&nrm=iso\&tlng=pt.

doi.

10.7784/rbtur.v12i3.1354

Guillaumon, S. (2011). Gestão de turismo, cultura e identidades religiosas: ensaio de um novo conceito com base na compreensão do território. Observatório de Inovação do Turismo, 6(2), 1-25. Recuperado de http://www.spell.org.br/documentos/ver/226/gestao-de-turismo--culturae-identidades-religiosas--ensaio-de-um-novo-conceito-com-base-nacompreensao-do-territorio

Gursoy, D., Jurowski, C. A., \& Uysal, M. (2002). Resident attitudes: A structural modeling approach. Annals of Tourism Research,29(1), 79105. https://doi.org/10.1016/S0160-7383(01)00028-7

Instituto Brasileiro do Turismo. (2019). Brasil ganha destaque na imprensa alemã. Brasil: Embratur. Recuperado de http://www.embratur.gov.br/piembraturnew/opencms/salalmprensa/noticias/arquivos/Brasil_ganha_destaque_n a_imprensa_alema.html

Jaluska, T. \& Junqueira, S. (2012). A utilização dos espaços sagrados pelo turismo religioso e suas possibilidades como ferramenta auxiliar para o estabelecimento do diálogo entre as nações. Turismo: Visão e Ação, 14(3), 337-348. Recuperado de http://www.spell.org.br/documentos/ver/8985/a-utilizacao-dos-espacossagrados-pelo-turismo-religioso-e-suas-possibilidades-como- 
ferramenta-auxiliar-para-o-estabelecimento-do-dialogo-entre-as-nacoes

Jornal de Turismo. (2015, 3 de abril). Turismo religioso movimenta a economia de diversas regiões do Brasil. Brasil: Jornal de Turismo. Recuperado de https://www.jornaldeturismo.tur.br/noticias/destinos/65092-turismoreligioso-movimenta-a- economia-de-diversas-regioes-do-brasil.

Jornal Folha de São Paulo. (2018, 21 de junho). Romaria leva 2,5 milhões de pessoas a Trindade (GO): a festa é considerada um dos maiores eventos religiosos do país e vai de 22 de junho a $1^{\circ}$ de julho. Brasil: Folha de São Paulo. Recuperado de https://www1.folha.uol.com.br/turismo/2018/06/romaria-leva-25-milhoesde-pessoas-a-trindade-go.shtml.

Kunt, S., \& Meydan-uygur, S. (2019). Seven Churches of the Revelation Visited in Route Tourism in Turkey. International Journal of Professional Business Review, 4(1), 32-52.

Maio, C. A. (2004). Turismo religioso e desenvolvimento local. Publicatio Uepg: Ciências Humanas, Linguística, Letras e Artes, 12 (1), 53-58. Recuperado de http://www.revistas2.uepg.br/index.php/humanas/article/view/503. doi: 10.5212/publ.humanas.v12i1.503

Mazaro, R. M. (2017). Inovação em Turismo e Competitividade Regional: abordagem conceitual e ensaio de aplicação. RTA - Revista Turismo em Análise, 28(1), 1-18. Recuperado de https://www.revistas.usp.br/rta/article/view/108119/128201. doi. 10.11606/issn.1984-4867.v28ilpl-18

Ministério do Turismo. (2015, 12 de janeiro). Turismo religioso continua em alta no Brasil: As viagens motivadas pela fé mobilizaram cerca de 17,7 milhões de peregrinos em 2014, segundo estimativas do Ministério do Turismo. Brasil: MTur. Recuperado de http://www.turismo.gov.br/ultimasnoticias/712-turismo-religioso-continua-em-alta-no- brasil.html

estrangeiros é a Internet. Brasil: Mtur. Recuperado de http://www.turismo.gov.br/\%C3\%BAltimas-not\%C3\%ADcias/6516-principalfonte-de-informa\%C3\%A7\%C3\%A3o-de-estrangeiros-\%C3\%A9-ainternet.html

(2018, 28 de setembro). Turismo religioso ganha espaço na Expo Cristã: viagens para fortalecer a fé estão entre produtos apresentados na maior exposição nacional de serviços e entretenimento voltados para o público cristão em SP. Brasil: MTur. Recuperado de http://www.turismo.gov.br/component/content/article.html? id= 
Montanari, M. G., \& Giraldi, J. M. E. (2013). Competitividade no turismo: uma comparação entre Brasil e Suíça. RBTUR - Revista Brasileira de Pesquisa em Turismo, 7(1), 92-113. Recuperado de https://rbtur.org.br/rbtur/article/view/564. doi.10.7784/rbtur.v7i1.564

Mora-jácome, V., Ludeña-reyes, A., Ochoa-ochoa, T., \& Sánchez-cevallos, E. (2018). Motivaciones del Turista Religioso - Peregrino y su Satisfacción. International Journal of Professional Business Review, 3(1), 5068.

Moretti, S. L. A., Bertoli, B. J., \& Zucco, F. D. (2016). A imagem de Blumenau no Instagram: um estudo sobre destino turístico em redes sociais usando equações estruturais. Caderno Virtual de Turismo, 16(1), 126-140. Recuperado de http://www.spell.org.br/documentos/ver/42135/aimagem-de-blumenau-no-instagram--um-estudo-sobre-destino-turisticoem-redes-sociais-usando-equacoes-estruturais. $10.18472 /$ cvt.16n1.2016.1045

Mota, K. C. N. (2011). Marketing turístico: tecnologia em hotelaria. Fortaleza, CE: UAB/IFCE.

Nunes, T. M., \& Platt, A. A. (2012). The event organization as a marketing strategy for the tourism in Florianópolis. Book of Proceedings - Tourism and Management Studies International Conference Algarve, University of the Algarve, Portugal, 1.

Oliveira, A. \& Guerra, P. (2016). Espaços urbanos entre a cultura, a imagem e a intervenção: Uma reflexão a partir de três intervenções na cidade do Porto. Cidades, Comunidades e Territórios, (32), 118-131. Recuperado de https://revistas.rcaap.pt/cct/article/view/10034. doi: 10.15847/citiescommunitiesterritories.jun2016.032.art07

Oliveira, E. S. (2008). Impactos socioambientais e econômicos do turismo e suas repercussões no desenvolvimento local: o caso de Itacaré - Bahia (Dissertação de mestrado). Universidade Estadual de Santa Cruz, Universidade Federal da Bahia, Ilhéus, BA, Brasil. Recuperado de http://www.vesc.br/cursos/pos_graduacao/mestrado/turismo/dissertaca o/mono_elton_silva.pdf

Pereira, C. (2017). O Legado Missionário e o Turismo - Dehonianos em Moçambique. Rosa dos Ventos - Turismo e Hospitalidade, 9(4), 656-674.

Pezzi, E., \& Santos, R. J. (2012, novembro). A experiencia turística e o turismo de experiencia: aproximações entre a antropologia e o marketing. Anais 
do VIl Seminário em Tursimo do Mercosul - Semintur, Tursimo e Paisagem: relação complexa. Caxias do Sul, RS, Brasil, 7.

Portuguez, A. P. \& Teubner Jr., F. J. (2001). Turismo, conservação ambiental e planejamento urbano em "cidades históricas": o caso de São Mateus (ES). In A. P. Portuguez, Consumo e espaço: turismo, lazer e outros temas. São Paulo, SP: Roca.

Quezado, I., Frota, A. J. A., Costa, J. S., Arruda, D. M. O., \& Mota, G. (2016). Só Jesus na Causa: Fé e Percepção de Crowding em Evento Religioso. Revista Brasileira de Marketing, 15(4), 486-495.

Ramos, D. M., \& Costa, C. M. (2017). Turismo: tendências de evolução. PRACS - Revista Eletrônica de Humanidades do Curso de Ciências Sociais da UNIFAP, 10(1), 21-33. Recuperado de https://periodicos.unifap.br/index.php/pracs/article/view/2843/dinav10n 1 .pdf. doi. 10.18468/pracs.2017v10n 1

Revista Exame. (2013, 17 de janeiro). As 10 cidades brasileiras preferidas pelos turistas e por quê. Brasil: Revista Exame. Recuperado de https://exame.abril.com.br/brasil/os-10-destinos-brasileiros-preferidospelos-turistas/

Rosendahl, Z. (1996). Cidade e religião: a expressão do sagrado no urbano. In Z. Rosendahl, Espaço e religião: uma abordagem geográfica. Rio de Janeiro, RJ: EURJ.

(2008). Os caminhos da construção teórica: ratificando e exemplificando as relações entre espaço e religião. In Z. Rosendahl \& R. L. Corrêa, Espaço e cultura: pluralidade temática. Rio de Janeiro, RJ: UERJ.

Santos, A. J. C., Abreu, I. B., Costa, S. R., Boahid, L. C. M., \& Pereira, R. C. P. (2012, outubroo). Turismo e experiencia: inovação e criatividade na feira da Praia grande em São Luís - MA. Anais do Simpósio de Excelência em Gestão e Tecnologia: Gestão, Inovação e Tecnologia para a Sustentabilidade - IX SEGeT. Resende, RJ, Brasil, 9.

Santos, E. E. (2010). Análise do turismo sob a perspectiva do conhecimento geográfico. Turismo: Visão e Ação, 13(1), 131-132. Recuperado de https://siaiap32.univali.br/seer/index.php/rtva/article/view/2439/1869. doi: 10.14210/rtva.v13n1.p131-132

Sanchez, P., \& Fernandez-hernandez, R. (2019). Mayrit On: Un Nuevo Turismo Cultural-Religioso. International Journal of Professional Business Review, $4(1), 81-93$. 
Schneider, M. \& Santos, M. M. C. D. (2015). A hospitalidade sob a ótica do romeiro na romaria ao santuário de Nossa Senhora de Caravaggio Farroupilha/RS e seu corolário no conceito de turismo religioso. Turismo: Visão e Ação, 17(2), 323-353. Recuperado de https://siaiap32.univali.br/seer/index.php/rtva/article/view/7955. doi: 10.14210/rtva.v17n2.p323-353

Sebrae - SP. (2017). Entendendo o atrativo turístico. Cadernos de atrativos turísticos. Brasil: Sebrae. Recuperado de http://www.sebrae.com.br/sites/PortalSebrae/ufs/sp/bis/serie-apresentaoportunidades-e-tendencias-no-setor-deturismo,el6a6d461ed47510VgnVCM1000004c00210aRCRD

Serrallonga, S. A., \& Hakobyan, k. (2011). Turismo religioso y espacios sagrados: uma porpuesta para los santuários de Catalunya. Revista Iberoamericana de Turismo, 1(1), 63-82. Recuperado de http://www.seer.ufal.br/index.php/ritur/article/view/241/184.

Silva, A. M. M. X., \& Silva, R. C. (2017). Turismo e Trabalho: Uma Análise do Destino Religioso Santa Cruz - RN. Revista Hospitalidade, 14 (2), 1-23.

Silva, G. V., Pontes, A. N., Batalha, S. S. A., \& Bentes, R. S. (2014). Turismo religioso: estudo do impacto econômico do Círio de Nazaré na cidade de Belém, Pará. Revista Turismo: Visão e Ação, 16(2), 273-292.

Silva, V. H., Chagas, M. M., \& Marques Junior, S. (2016). O papel da imagem do lugar e dos impactos percebidos e suas influências no apoio dos residents ao desenvolvimento do turismo: um estudo em Genipabu. Revista Interface, 13(1), 5-19.

Silveira, E. J. S. da. (2007). Turismo Religioso no Brasil: uma perspectiva local e global. Turismo em Análise, 18(1), 33-51. Recuperado de http://www.revistas.usp.br/rta/article/view/62606/65394

Soares, E. D., \& Ramos, H. R. (2018). Siga o Líder: A Influência de uma Liderança Carismática Religiosa no Crescimento Turístico da Cidade de Nova Trento em Santa Catarina. PODIUM Sport, Leisure and Tourism Review, 7(3), 390-401.

Soifer, J. (2005). Empreender turismo e ecoturismo. Rio de Janeiro, RJ: Qualitymark.

Souza, T. R. (2010, julho). Lazer e turismo: reflexões sobre suas interfaces. Anais do VI Seminário de Pesquisa em Turismo do Mercosul - Semintur, Saberes e fazeres no Turismo: Interfaces. Caxias do Sul, RS, Brasil, 6. 
Tavares, A. de M. (2002). City tour. São Paulo, SP: Aleph.

Tineu, R. \& Fragoso, N. D. (2010). Estratégias de comunicação boca a boca para o turismo. Revista Brasileira de Marketing, 8(2), 116-145. Recuperado de http://www.revistabrasileiramarketing.org/ojs2.2.4/index.php/remark/article/view/2136. doi: 10.5585/remark.v8i2.2136

Trindade, B. S., César, P. A. B., \& Vianna, S. L. G. (2019). Governança do Turismo: Planejamento e Gestão Local e Regional em Gramado-RS, Brasil. Rosa dos Ventos - Turismo e Hospitalidade, 11 (3), 653-663.

Zorzi, M., \& Cerqueira, F. V. (2010, julho). Atrativos turísticos e patrimônio cultural: o olhar do poder público e da comunidade local no município de Jaguarão - RS. Anais do VI Seminário em Tursimo do Mercosul Semintur, Saberes e fazeres no turismo: Interfaces. Caxias do Sul, RS, Brasil, 6.

Xavier, A. C. (2006). O papel social do turismo. Caderno Virtual de Turismo, 6(1), 9-15. 